\title{
Cuestiones historiográficas relativas a la Virgen de Luján
}

\author{
Enrique Ciro Bianchi ${ }^{\circ}$ \\ Facultad de Teología - Pontificia Universidad Católica Argentina \\ qbianchi@gmail.com \\ Recibido 20.04.2021/ Aprobado 20.05.2021 \\ DOI: $h$ ttps://doi.org/10.46553/teo.58.135.2021.p11-40
}

\section{RESUMEN}

El presente artículo intenta establecer un diálogo entre dos corrientes de estudios históricos sobre la Virgen de Luján. Por una parte, tenemos las investigaciones surgidas en el seno de la Iglesia, entre las que se destacan los trabajos de Salvaire, Presas y Durán. Pero -sobre todo a partir de la década de 1980- han aparecido estudios que abordan la historia de la Iglesia desde una óptica no confesional. Estos investigadores también se interesaron en el fenómeno de Luján y algunas de sus interpretaciones entran en conflicto con la tradición eclesial. Creemos que puede ser muy enriquecedor establecer un diálogo entre ambas miradas. Para poder hacerlo, necesitamos pautas metodológicas y en este trabajo intentamos delinearlas a partir de la propuesta de Bernard Lonergan. Luego, a modo de ejemplo, aplicamos ese método en un diálogo dialéctico alrededor de dos tópicos: el origen religioso de la Villa de Luján y las motivaciones para la construcción de la Basílica.

Palabras clawe: Luján; Historiografía; Crónica; Interpretación; Ampliación de horizontes

\section{Historiographical Issues Concerning the Virgin of Luján}

\section{ABstRact}

This article attempts to establish a dialogue between two streams of historical studies on the Virgin of Luján. On the one hand we have the investigations that have arisen within the Church, among which the works of Salvaire, Presas and Durán stand out. But-especially since the 1980s- studies have appeared that approach the

\footnotetext{
- El autor es profesor de Teología Pastoral en la Facultad de Teología de la UCA.
} 
history of the Church from a non-confessional perspective. These researchers were also interested in the phenomenon of Luján and some of its interpretations conflict with ecclesial tradition. We believe that it can be very enriching to establish a dialogue between the two perspectives. In order to do this, we need methodological guidelines and in this work we try to delineate them from the proposal of Bernard Lonergan. Then, as an example, we applied this method in a dialectical dialogue around two topics: the religious origin of the Town of Lujan and the motivations for the construction of the Basilica.

Key Words: Luján; Historiographical; Chronicle; Interpretation; Broadening horizons

\section{Introducción: distintas miradas}

El culto a la Virgen de Luján comienza su historia hacia el año 1630. Los estudios sobre los orígenes de la devoción lujanense tienen como cimiento dos antiguas crónicas. La primera, escrita en 1737 por el fraile mercedario Pedro Santa María de Nolasco; ${ }^{1}$ la segunda por el franciscano Antonio Oliver alrededor de 1780 y editada en 1812 por Felipe José Maqueda. ${ }^{2}$ Sobre esta base, se yergue la obra de los dos grandes historiadores de la Virgen de Luján: el sacerdote vicentino Jorge María Salvaire (1847-1899), ${ }^{3}$ y el padre Juan Antonio Presas (1912-2005). ${ }^{4}$

1 Santa María escribe su relato al comparecer como testigo -bajo juramento- ante un tribunal eclesiástico conformado en 1737 para certificar el origen y culto de la Virgen de Luján. Este contexto le otorga un gran valor documental a s ucrónica. A lo que se suma el hecho de que el testigo fue Capellán interno en Luján y dice haber conocido a los personajes principales de su relato: el Negro Manuel, Ana de Matos y el padre Montalbo (cf. Juan A. Presas, Nuestra Señora de Luján: estudio crítico-histórico: 1630-1730 (Buenos Aires: Junta Catequística Diocesana de Morón, 1980), 36-38.

2 Felipe José Maqueda fue un sacerdote que vivió prácticamente todo su ministerio en Luján (1770-1812). Junto con su tío Carlos José Vejarano y su hermano Gabriel Maqueda condujeron el Santuario durante casi setenta años. Estos datos biográficos nos permiten suponer que Maqueda estaba muy familiarizado con la tradición oral de Luján. Salvaire afirma que -además de tomar el relato de Oliver-, se apoyó «en la tradición constante transmitida de padres a hijos, como en las relaciones que había recibido de su piadoso tío, Don Carlos José de Vejarano, celoso capellán de Luján y de un pardo esclavo de la Virgen Ilamado Perico, anciano de una virtud eminente que había consumido su larga existencia al servicio de la Virgen de Luján y finalmente en los muchos documentos auténticos que se guardaban en el Archivo del Santuario, o figuraban en el importante libro que el Tribunal Eclesiástico mandó formar el 1737» (cf. Ibid., 41). Sobre la figura de Oliver cf. Mario Poli, «La Virgen de Lujan y su cronista franciscano Fray Antonio Oliver Feliu ofm (Palma de Mallorca 1711-Buenos Aires 1787)», Nuevo Mundo 8. (2007): 81-106.

3 En 1885 publicó en dos tomos su Historia de la Virgen de Luján. Su origen, su santuario, su villa, sus milagros y su culto.

4 Sus investigaciones se sintetizan en: Presas, Nuestra Señora de Luján: estudio critico-histórico: 1630-1730. En esta obra recoge -y amplía- lo presentado en tres de sus libros 
Entre los demás historiadores que se ocuparon del fenómeno lujanense, ${ }^{5}$ merece una mención especial el doctor Raúl Molina (1897-1973), miembro de la Academia Nacional de Historia, y reconocido en su tiempo como el mayor especialista en historia bonaerense del siglo XVII. Sin su trabajo la obra de Presas no hubiera sido posible. Investigando en orden a realizar un Diccionario Biográfico de los primeros habitantes de Buenos Aires encontró -para su sorpresa y la de muchos- que los personajes nombrados en las antiguas crónicas lujanenses se correspondían con personas reales cuya existencia y actuación estaba documentada. ${ }^{6}$

Sobre esta base Juan Guillermo Durán, sacerdote de la Arquidiócesis de Mercedes Luján, ha desarrollado numerosos estudios recientes, sobre todo acerca de las figuras del Negro Manuel y el padre Salvaire, ambos en proceso de canonización desde 2016. Este historiador es el postulador de la causa de canonización del Negro Manuel y en 2019 presentó una biografía del fiel esclavo de la Virgen.7 Sobre el padre Salvaire, el más célebre capellán de la Virgen de Luján, Durán escribió cuatro voluminosos estudios entre 1998 y $2009 .{ }^{8}$ Luego, en 2016 publicó un quinto libro a modo de síntesis de divulgación. ${ }^{9}$

anteriores: Nuestra Señora en Luján y Sumampa (1974), La estancia del Milagro (1977) y Luján ante la ciencia y la fe (1978).

5 Otras obras que merecen nombrarse son: Antonio Scarella, Pequeña historia de Nuestra Señora de Luján. Su culto, su santuario y su pueblo (Buenos Aires, 1925); Enrique Udaondo, Reseña histórica de la Villa de Luján (Luján: Talleres gráficos San Pablo, 1939); Antonio Guérault, La Virgen de Luján y su Santuario. Sintesis histórica. Evocaciones (Luján, 1972).

6 Presentó su trabajo en la Academia Nacional de Historia en 1967 bajo el título: "Leyenda e historia de la Virgen de Luján". Allí afirma: "con las noticias que acabamos de dar sobre los acontecimientos y las personas que rodearon el milagro de Luján, hoy ya no se puede afirmar que fue una leyenda» (Boletín de la Academia Nacional de la Historia, 40, Buenos Aires, 151-197). Cf. Presas, Nuestra Señora de Luján: estudio crítico-histórico: 1630-1730, 54-59; Jorge Cortabarría, «Raúl A. Molina y la historia de la Virgen de Luján», en Temas de historia argentina y americana 6, ed. por Liliana M. Brezzo et al. (Buenos Aires: UCA, 2005), 67-87.

7 Juan Guillermo Durán, Manuel "Costa de los ríos": fiel esclavo de la Virgen de Luján (Buenos Aires: Ágape Libros, 2019). Sobre el Negro Manuel en el misterio de Luján cf. Sergio Gomez Tey, El Negro Manuel y su vida en la historia de la Virgen de Luján (Buenos Aires: Ágape Libros, 2017 ).

8 Cf. Juan Guillermo Durán, El padre Jorge María Salvaire y la familia Lazos de Villa Nueva: un episodio de cautivos en Leubucó y Salinas Grandes : en los orígenes de la Basilica de Luján, 1866-1875 (Buenos Aires: Paulinas, 1998); Juan Guillermo Durán, En los toldos de Catriel y Railef: la obra misionera del Padre Jorge María Salvaire en Azul y Bragado: 1874-1876 (Buenos Aires: Facultad de Teología, UCA, 2002); Juan Guillermo Durán, De la frontera a la villa de Luján: el gran Capellan de la Virgen Jorge Maria Salvaire, CM (1876-1889) (Buenos Aires: Bouquet Ed., 2008); Juan Guillermo Durán, De la frontera a la villa de Luján: los comienzos de la gran basilica: Jorge María Salvaire, CM, 1890-1899 (Buenos Aires: Facultad de Teología, UCA, 2009).

9 Juan Guillermo Durán, Jorge Maria Salvaire, C. M., Gran apóstol de la Virgen de Luján, "Cual otro Negro Manuel" (Buenos Aires: Talita Kum Ediciones, 2016). 
A esto hay que agregar los trabajos de muchos investigadores del ámbito no confesional que se interesan en la historia de los fenómenos religiosos en la Argentina. Esta tendencia comenzó en la década de 1980. La vuelta de la democracia hizo que los historiadores ampliaran sus ámbitos de interés. La motivación era sobre todo política: se buscaba entender el rol que había jugado la Iglesia en la historia del país. Dejemos que lo explique Roberto Di Stéfano, uno de los protagonistas de ese movimiento:

\begin{abstract}
«Es desde fines de la década de 1980 que se conforma un campo de estudios que puede autonomizarse de las demandas, tanto confesionales como ideológicas, que coartaban su estructuración. Los trabajos buscaron desprenderse de la retórica teológica que parecía ineludible al hablar del catolicismo. Surgió una historia de la Iglesia y del catolicismo que podía pensar su objeto con instrumentos y reglas ajenos a su propia lógica. Esos primeros trabajos tuvieron un norte claro: tratar de entender el rol que había jugado la Iglesia como actor político en el siglo XX. Esa premisa estaba pautada por el clima de la naciente democracia de 1983 y la búsqueda de las matrices autoritarias que habían condenado a la Argentina a una inestabilidad endémica desde, al menos, 1930. La Iglesia -y las Fuerzas Armadas, y en menor grado otras corporaciones, como los sindicatos y los empresarios- eran objetos privilegiados de esta exploración, en la que distintos trabajos intentaban rastrear el origen de la Argentina autoritaria. Es por eso que la política fue el primer interés que llevó a la historia de la Iglesia a constituirse en un subcampo, en el marco de un renacimiento general de la actividad académica en los años de $1980 \gg .{ }^{10}$
\end{abstract}

Este movimiento generó una importante producción sobre historia de la Iglesia argentina con una óptica distinta a la confesional. Esto se vio favorecido por la multiplicación de becas para investigadores del CONICET y el aumento de profesores-investigadores que trajo aparejada la creación de nuevas universidades en las últimas décadas. Entre estos nuevos estudios encontramos una buena cantidad de investigaciones sobre los orígenes lujanenses, ${ }^{11}$

10 Roberto Di Stefano y José Zanca, «lglesia y catolicismo en la Argentina: medio siglo de historiografía», Anuario de Historia de la Iglesia 24 (2015): 15-45, 32. Ver también: Roberto Di Stefano, «De la teología a la historia: un siglo de lecturas retrospectivas del catolicismo argentino», Prohistoria 6 (2002): 173-201.

11 En la etapa previa a este resurgir de la década de 1980 debemos nombrar el capítulo sobre Luján en la Historia de la provincia de Buenos Aires dirigida por Ricardo Levene: Guillermina 
especialmente de historiadores relacionados con la Universidad Nacional de Luján como por ejemplo: Patricia Fogelman, ${ }^{12}$ María Elena Barral, ${ }^{13}$ Dedier Norberto Marquiegui, ${ }^{14}$ Jesús Binetti $^{15}$ y Federico Suárez. ${ }^{16}$

Hoy en día la gran mayoría de estudios históricos sobre la actuación de la Iglesia en Argentina provienen de esta vertiente. Creemos que una teología que pretenda profundizar en el misterio de Dios expresado en la Virgen de Luján no puede ser insensible a este movimiento. Pero como prolegómeno de todo diálogo es necesario establecer algunas pautas metodológicas que nos guíen en este camino. Eso es lo que humildemente intentaremos en este artículo y lo haremos de la mano de la propuesta metodológica de Bernard Lonergan. La exposición tendrá tres partes. En primer lugar, presentaremos someramente el método teológico de Lonergan en lo relativo a la investigación histórica (2). Luego explicitaremos

Sors de Tricerri, «Luján», en Historia de la Provincia de Buenos Aires y formación de sus pueblos, ed. por Ricardo Levene (La Plata: Taller de Impresiones Oficiales, 1941)

12 Patricia Fogelman, «Reconsideraciones sobre los orígenes del culto a la Virgen de Luján», Entrepasados 12.23 (2002): 123-148; Patricia Fogelman, «Dos exvotos contra el Estado liberal: la Basílica y el libro de Salvaire sobre la historia del culto de Luján», en El culto mariano en Luján y San Nicolás: religiosidad e historia regional, ed. por Patricia Fogelman, Mariela Ceva, Claudia Touris (Buenos Aires: Biblos, 2013), 25-49; Patricia Fogelman, «Exvotos y secularización: libro y santuario de la Virgen de Luján, fines del s. XIX», Revista Brasileira de História das Religiões 31 (2018): 167-202.

13 María Elena Barral, De sotanas por la Pampa: religión y sociedad en el Buenos Aires rural tardocolonial (Buenos Aires: Prometeo, 2007); María Elena Barral, Curas con los pies en la tierra: Una historia de la Iglesia en la Argentina contada desde abajo (Buenos Aires: Penguin, 2016). Esta última obra tiene todo un capítulo dedicado al padre Jorge M. Salvaire.

14 Dedier Marquiegui, Estancia y poder político en un partido de la campaña bonaerense: Luján, 1756-1821 (Buenos Aires: Biblos, 1990); Dedier Marquiegui y Jesús Binetti, Lapides clamabunt (las piedras hablarán): el debate sobre la construcción de la Basilica de Nuestra Señora de Luján (Trabajo presentado ante el Grupo de Estudios de Historia de la Iglesia, Instituto Ravignani: Facultad de Filosofía y Letras de la Universidad de Buenos Aires, 2005); Dedier Marquiegui, «Para que lo pueble la gente que se conoce derrotada (por los indios). Precisiones documentales sobre los orígenes del Luján urbano», Red Sociales. Revista del Departamento de Ciencias Sociales 6 (2019): 13-56.

15 Jesús Binetti, El augusto recinto. Conflictos y debates tras la construcción de la Basilica de Luján (Luján: Librería de Mayo, 2007); Jesús Binetti, «La cruz sin espada. Patrimonio, tradición e historia del Luján temprano, 1671-1742. $1^{\circ}$ parte», Red Sociales. Revista del Departamento de Ciencias Sociales 4 (2014): 52-80; Jesús Binetti, «La cruz sin espada. Patrimonio, tradición e historia del Luján temprano, 1671-1742. $2^{\circ}$ parte», Red Sociales. Revista del Departamento de Ciencias Sociales 3 (2016): 3-34.

16 Federico Suárez, Luján antes de convertirse en Villa (Buenos Aires: Grupo EFE, 2013); Jesús Binetti y Federico Suárez, Una virgen para el pago: historia y patrimonio del Luján, 1580 1740 (Ituzaingó: Cienflores, 2016). 
algunos fundamentos que encontramos en la raíz de los diversos planteos en diálogo (3) y por último abordaremos desde la dialéctica dos cuestiones que presentan un conflicto de interpretación histórica (4). Estas son: el origen religioso de la Villa de Luján (4.1) y las motivaciones de la construcción de la Basílica (4.2).

\section{La historia y sus conflictos en el método teológico de Lonergan}

\subsection{La historia como especialización funcional}

Para pensar el modo en que debemos llevar adelante las investigaciones históricas desde la teología resulta muy luminosa la propuesta de Lonergan. ${ }^{17}$ Este jesuita canadiense ha realizado un importante aporte al desarrollo de la teología en las últimas décadas proponiendo un método trascendental para hacer teología a partir de las cuatro operaciones fundamentales del espíritu humano en búsqueda de su realización: experimentar, entender, juzgar y decidir. A través de ellas el ser humano da cauce a su deseo de una vida auténtica. Pueden expresarse en cuatro preceptos trascendentales: sé atento, sé inteligente, sé razonable y sé responsable. En la medida en que alguien sigue estos preceptos se orienta hacia su propia realización y se convierte en una persona auténtica. Por el contrario, si se aparta de su cumplimiento, pierde su propia identidad y justifica sus malas acciones mediante su propia alienación que surge de los falsos razonamientos y de las ideologías. ${ }^{18}$

En cierto modo todos conocemos y aplicamos el método trascendental en nuestra vida cotidiana en la medida en que somos atentos, inteligentes, razonables y responsables. Lonergan lo que propone es una objetivación de estas operaciones que las ubiquen

17 Bernard Lonergan, Método en teología (Salamanca: Sígueme, 2006).

$18 \mathrm{Cf}$. Pablo Figueroa, «Hacia una fundamentación del hacernos a nosotros mismos en la ética existencial metódica de B. Lonergan», en Dar razón de nuestra esperanza. El anuncio del Evangelio en una sociedad plural. XXX Semana Argentina de Teología, ed. por Sociedad Argentina de Teología (Buenos Aires: Agape libros, 2012), 467-476, 470. 
en un grado superior de consciencia y desde allí desarrolla pautas metodológicas válidas para toda investigación y las aplica a la investigación teológica. Para ello, llama a ejercer estas cuatro operaciones fundamentales en las dos fases de la teología: auditus fidei e intellectus fidei. Esto resulta en ocho especializaciones funcionales para desarrollar el pensamiento teológico. Al momento de la asimilación de la tradición (auditus fidei) corresponderán las cuatro primeras especializaciones: 1) investigación, 2) interpretación, 3) historia y 4) dialéctica. En el momento de reflexión a partir de los datos adquiridos (intellectus fidei) se desarrollarán: 5) explicitación de los fundamentos, 6) desarrollo doctrinal, 7) comprensión sistemática y 8) comunicación. ${ }^{19}$ Como podemos ver en esta subdivisión del trabajo teológico, la historia resulta la tercera especialización funcional. Al juicio histórico (sé razonable) se llega después de ser atentos (1. investigación) e inteligentes (2. interpretación). Sólo así se llega a ser responsables en el juicio de valor sobre los conflictos de interpretación (4. dialéctica).

Al estudio de la historia como especialización funcional de la teología Lonergan le dedica dos capítulos de su obra Método en teología. Allí explica que la naturaleza precisa de la investigación histórica es algo difícil de determinar porque no siempre se tiene una teoría del conocimiento satisfactoria. El conocimiento histórico es una instancia del conocimiento humano y como tal no se reduce sólo a experimentar, sino que es un compuesto de experimentar, entender y juzgar. Por tanto, habrá una experiencia histórica, un entender histórico y un juzgar histórico. ${ }^{20}$ De aquí que afirme que:

«El trabajo del historiador no consiste solamente en hallar testimonios, examinar su credibilidad y hacer un tejido con lo que ha encontrado creíble. Precisamente no es eso, porque la experiencia histórica es una cosa, y el conocimiento histórico es otra enteramente distinta. El hacer un tejido de testimonios creíbles simplemente reedita la experiencia histórica. No llega

$19 \mathrm{Cf}$. Lonergan, Método en teología, 127.

$20 \mathrm{lbid}, 174$. 
al conocimiento histórico, que percibe lo que se estaba gestando, lo que la mayor parte de los contemporáneos no llegó a conocer». ${ }^{21}$

Sobre esta base, Lonergan presenta una reflexión filosófica sobre el tiempo y avanza con una explicación sobre nuestra experiencia del tiempo. Allí, para ayudarnos a entender el trabajo del historiador, explica que el presente sicológico penetra en el pasado por medio de los recuerdos, tanto individuales como colectivos. Éstos se expresan de diversas maneras: cantos, narraciones, monumentos y todo tipo de huellas que una comunidad deja a la posteridad. Ese es el campo propio de la investigación histórica. Ahora bien, este campo está fundado en la naturaleza de la acción individual y colectiva. La cual tiene un aspecto consciente y un aspecto inconsciente. El aspecto consciente se da en el flujo de actos conscientes y dotados de significación. Por eso:

«La significación es, entonces, un elemento constitutivo del flujo consciente, y es normalmente el elemento de control de la acción humana. Es precisamente este papel constitutivo de la significación en el control de la acción humana el que fundamenta la peculiaridad del campo abierto a la investigación histórica».22

En la medida en que una comunidad desarrolla su vida, en la medida que se da un campo común de experiencia, un entender común y unos juicios comunes, se van dando significaciones comunes. Pero entender lo que la gente quiso significar no es propiamente la tarea del historiador sino del exégeta (segunda especialización funcional). El historiador debe ir más allá y comprender lo que se iba gestando en esa comunidad:

«Por "irse gestando" entiendo la exclusión de la mera repetición de una rutina. Entiendo el cambio que originó la rutina y su diseminación. Entiendo el proceso y el desarrollo pero, no menos, la decadencia y la desintegración. Cuando las cosas cambian inesperadamente la gente piadosa dice: "El hombre propone pero Dios dispone". Al historiador le corresponde mostrar

21 lbid., 179.

22 lbid, 171. Ya había explicado que la significación se da en cuatro campos: sentido común, teoría, interioridad y trascendencia (Ibid., 84s). 
cómo dispuso Dios los asuntos, pero no con especulaciones teológicas, ni con una dialéctica cosmo-histórica, sino por medio de los agentes humanos particulares».23

A la historia le concierne el drama de la vida, lo que resulta de las acciones humanas. Pero no solo de ellas sino también de sus defectos, sus inadvertencias, sus deficiencias en la acción. Se trata de determinar lo que los contemporáneos no saben, porque en la mayoría de los casos la gente no sabe lo que se está gestando. Luego de un proceso de investigación e interpretación de los testimonios del pasado la especialización funcional de la historia deberá establecer los hechos ocurridos y presentarlos en el marco de un proceso histórico.

Para cumplir con este cometido y reducir lo más posible el relativismo histórico la ciencia histórica ha desarrollado el método histórico crítico. Lonergan presenta los procedimientos que éste debe desarrollar para presentar resultados con cierta objetividad pero aclara que la eliminación del relativismo nunca puede ser total. Las ideas del historiador, sus juicios de valor, o su cosmovisión pueden influir de tal manera que obstaculicen el acceso a un conocimiento objetivo del pasado. Sostiene que: "si he llegado a adoptar la idea de que las técnicas de la historia crítica no son capaces de eliminar totalmente el relativismo histórico, afirmo con tanta mayor firmeza que ellas pueden efectuar, y que efectúan de hecho, una eliminación parcial». ${ }^{24}$

La búsqueda de una historiografía aséptica, sin ningún juicio del historiador, con una objetividad similar a la de las ciencias naturales, es algo irrealizable. Lonergan explica claramente esa imposibilidad: «el estudio de la historia difiere del estudio de la naturaleza física, química y biológica. Hay una diferencia en sus objetos, ya que los objetos de la física, la química y la biología no están constituidos en parte por actos de significación». ${ }^{25}$ La historia, a diferencia de 
las ciencias naturales, busca interpretar actos que están dotados de sentido por el espíritu humano. Además, la historia escrita es una obra humana y -como tal- siempre llevará una huella de su creador.

\subsection{El ejercicio dialéctico para abordar los conflictos de interpretación}

En el método teológico que propone Lonergan luego de la especialización funcional historia (la tercera) viene la dialéctica (la cuarta). Esta se ocupa de los conflictos. En primer lugar de los conflictos que afectan a los movimientos cristianos. Pero también del conflicto que se suscita ante las diversas interpretaciones históricas o teológicas. Su objetivo es lograr un punto de vista englobante para entender las distintas posturas en oposición. Esto lleva a indagar las razones del conflicto para sacar a luz cuáles diferencias son irreductibles, cuáles son complementarias y susceptibles de ser armonizadas y cuáles se pueden ver como estadios sucesivos de un mismo proceso de desarrollo. Este trabajo requiere luego de la crítica. No todos los puntos de vista son coherentes ni todas las razones son fundadas. «El cristianismo no tiene nada que perder eliminando las razones infundadas, las explicaciones ad hoc, los estereotipos que engendran la sospecha, el resentimiento, el odio y la malevolencia». ${ }^{26}$

Muchas veces los conflictos de interpretación se dan porque los investigadores trabajan desde marcos conceptuales diversos e incompatibles. Para explicar esto Lonergan utiliza fecundamente la metáfora del horizonte. ${ }^{27}$ Éste representa una línea que marca el límite de nuestro campo de visión. Más allá del horizonte están los objetos que -al menos por ahora- no pueden ser percibidos. Dentro de nuestro horizonte están las cosas que actualmente podemos ver. Al igual que nuestro campo de visión, nuestro ámbito de conocimiento e intereses es limitado. Toda investigación se realiza en el interior de un horizonte. Esto es verdad aunque uno presuponga

27 lbid., 229 s. 
que no tiene ningún presupuesto. Como consecuencia, "uno encuentra muy fácilmente lo que se acopla a su propio horizonte y tiene muy poca habilidad para notar lo que nunca ha concebido ni entendido». ${ }^{28}$ De aquí que no sólo en el ejercicio de la crítica histórica sino en la investigación e interpretación previas puedan revelarse diferencias de horizontes. La historia crítica "promete resultados unívocos pero sólo si los historiadores parten desde puntos de vista comunes». ${ }^{29}$ Esto no siempre se da ya que a los mismos objetos se puede acceder desde perspectivas diversas. Los distintos horizontes pueden ser complementarios, o corresponder a distintas etapas de un mismo desarrollo, o directamente opuestos. La dialéctica se ocupará de los conflictos que surgen en este último caso.

Aquí es donde entra en juego la quinta especialización funcional: la explicitación de los fundamentos. A ésta le corresponde el esfuerzo por discernir los modelos de pensamiento subyacentes al investigador. Éste es el momento más personal en el que el teólogo busca explicitar el horizonte interior desde el cual se podrá aprehender el sentido de las doctrinas: «en la reflexión teológica sobre la religión vivida, hay que distinguir los diversos horizontes en el interior de los cuales las doctrinas religiosas pueden o no ser aprehendidas, y esta distinción es fundante». ${ }^{30}$

En este artículo intentaremos un ejercicio dialéctico entre diversas interpretaciones sobre dos hechos históricos relativos a la Virgen de Luján. En el proceso hemos respetado el orden propuesto por Lonergan y -luego de la investigación histórica- analizamos los conflictos para después buscar entender el horizonte en el que se mueve cada postura. Sin embargo, a la hora de exponer nos parece mejor comenzar por la explicitación de los fundamentos para luego explicar el ejercicio dialéctico con los principios establecidos. 


\section{Explicitación de los fundamentos de ambas miradas}

\subsection{Hacer historia desde un horizonte cristiano $^{31}$}

Quien adscriba personalmente a una cosmovisión cristiana verá al mundo como salido de las manos de Dios y a la historia humana acompañada por la providencia divina. El Dios en el que creemos los cristianos vive en una permanente comunicación amorosa con su creación. El Concilio Vaticano II presenta la doctrina de la Revelación en clave de auto comunicación divina que tiene su fuente última en el amor de Dios por su creación. Dios quiere dar a todos los seres humanos una plenitud de vida uniéndolos consigo en una comunión de amor y para ello se revela a Sí mismo y su voluntad. El culmen de esa comunicación divina es la encarnación de Jesucristo que se da en la plenitud de los tiempos. ${ }^{32} \mathrm{Al}$ encarnarse como hombre concreto y por tanto histórico, Dios transforma la historia y la deja preñada de su misterio. El Dios de Jesucristo no es un ser absolutamente trascendente incapaz de intervenir en la vida de las personas. Dios es providente con su creatura: actúa en la historia humana. Ésta se nos presenta a los creyentes como una urdimbre en la cual la libertad humana se conjuga con la acción salvífica de Dios.

Es debido a esta concepción de la historia, entendida como historia de salvación, por lo que la teología busca conocer a Dios no sólo en la Revelación tal como la consigna la Escritura interpretada en el marco de la tradición eclesial sino también rastreando sus huellas en el acontecer humano. Dios se ha revelado -y se sigue revelando- históricamente. De aquí que se considere a la historia como un verdadero lugar teológico. ${ }^{33}$ Una teología pretendidamen-

31 En este punto nos inspiramos en: Rafael Tello, Historia y liberación (Buenos Aires: Curso organizado por el Centro de estudios "Justicia y Paz", 1972); Hubert Jedin, "Storia della chiesa come storia della salvezza?», Critica Storica 2 (1962): 181-194; Ricardo Corleto, «La formación teológica del historiador de la Iglesia», Teología 66 (1995): 227-234.

32 Cf. DV 1-4.

33 La expresión lugar teológico designa la fuente del conocimiento teológico. Ya en el siglo XVI Melchor Cano distinguía entre lugares constitutivos de la revelación (Sagrada Escritura, Tradición no escrita) y lugares que interpretan la tradición (Iglesia universal, Concilios generales, Sumo Pontífice, etc.). También incluía en su numeración los alieni loci, que no son fuentes teoló- 
te ahistórica será siempre incompleta. Podrá decirnos cosas ciertas de Dios pero adolecerá de una raigambre profética capaz de iluminar la vida de las personas a las que se dirige.

La cuestión es compleja porque si aceptamos que Dios es también un actor histórico se presenta el problema de dilucidar cómo es esa acción. Estamos aquí en el ámbito de un misterio de fe que la reflexión creyente indaga permanentemente. La teología es una ciencia que busca penetrar racionalmente el misterio de Dios y su interacción con la humanidad. Misterio que es ante todo creído por la fe pero que es susceptible de ser penetrado por la razón. Dios es un infinito de inteligibilidad, según la feliz expresión de $\mathrm{H}$. de Lubac. ${ }^{34}$ Si bien nunca llegaremos a comprenderlo en toda su profundidad, el objeto de nuestra fe es razonable. Lo mismo sucede con el misterio de la acción de Dios en el mundo. Ésta no se da -por lo general- saltando las leyes de la naturaleza ni anulando la libertad de los hombres. Más bien hay que pensar que Dios mueve interiormente a sus creaturas con su "amor que ha sido derramado en nuestros corazones por el Espíritu Santo" (Rom 5,5). Esto produce efectos en la historia y es a través de ellos que la mirada de fe discierne la acción de Dios. Es lo que se conoce como discernimiento de los signos de los tiempos. De aquí que un acceso teológico a los hechos históricos no puede desconocer las complejidades del acontecer humano. Repitamos una afirmación de Lonergan que sintetiza esta idea: «al historiador le corresponde mostrar cómo dispuso Dios los asuntos, pero no con especulaciones teológicas, ni con una dialéctica cosmo-histórica, sino por medio de los agentes humanos particulares». ${ }^{35}$

gicas propiamente dichas sino fuentes auxiliares para la reflexión de la fe. Una de estas fuentes auxiliares es la historia (las otras son la razón humana y los argumentos filosóficos). Cf. Edward Schillebeeckx, Revelación y teología (Salamanca: Sígueme, 1969), 217.

34 Cf. Henri de Lubac, Por los caminos de Dios (Madrid: Encuentro, 1993), 93s.

35 Lonergan, Método en teología, 172. 


\subsection{Las investigaciones no confesionales sobre la vida de la Iglesia}

Intentemos ahora entender algunos de los fundamentos que subyacen en las investigaciones del ámbito "laico". Reconocemos que aquí estamos pisando un terreno no tan firme y quedamos abiertos a posteriores rectificaciones en la medida en que descubramos que partimos de algún presupuesto erróneo. En primer lugar debemos remitirnos a la explicación de Di Stéfano-Zanca a la que ya nos hemos referido: con el restablecimiento de la democracia en 1983 surgió un interés por indagar «las matrices autoritarias que habían condenado a la Argentina a una inestabilidad endémica desde, al menos, 1930». ${ }^{36}$ Con ese fin se buscó «tratar de entender el rol que había jugado la Iglesia como actor político en el siglo $X X{ }_{\gg}{ }^{37}$ Después de esta motivación política inicial vino una etapa en que las investigaciones no tenían como objeto principal la actuación institucional de la Iglesia sino las lógicas particulares del catolicismo con sus organizaciones e ideas. ${ }^{38}$

Especial atención prestan los trabajos de esta corriente a la década de 1930 en la que la Iglesia tuvo una enorme presencia en la vida social, confirmada por las grandes movilizaciones de los Congresos Eucarísticos y la organización del laicado a través de la Acción Católica. La describen como una institución con una enorme vocación por ocupar el centro de la escena nacional, que buscaba consolidar esa centralidad imponiendo una identificación entre ser católico y ser argentino. Postura que sintetizan con la expresión «mito de la nación católica». ${ }^{39}$ A partir de esta lectura, algunos investigadores ofrecen una versión virulentamente crítica sobre todas las expresiones de la vida de la Iglesia. Daría la impresión -en esos casos- que hay una tendencia a mirar a toda la Iglesia -y a todas las

36 Di Stefano y Zanca, «lglesia y catolicismo en la Argentina: medio siglo de historiografía», 32.

$37 \mathrm{lbid}$.

$38 \mathrm{lbid}, 39$.

39 Expresión acuñada por L. Zanatta y que -aunque se discute su contenido- ha tenido amplia repercusión en este ambiente (cf. Loris Zanatta, Del estado liberal a la nación católica: Iglesia y ejército en los origenes del peronismo, 1930-1943 (Buenos Aires: Universidad nacional de Quilmes, 1996)). 
expresiones religiosas- a través del prisma del catolicismo integral de esa década. Esto hace que con demasiada facilidad le atribuyan a un actor eclesial la vocación hegemónica y autoritaria que pudo haber tenido un sector en una determinada etapa histórica.

Aplicada a Luján, esta perspectiva tiende a ver los esfuerzos de la Iglesia por difundir su culto y la declaración de patrona de los argentinos como un paso más en la búsqueda por construir una hegemonía católica en la sociedad. El ejemplo más claro lo encontramos en los estudios sociológicos de E. Martín:

«En el esfuerzo que hace la Iglesia para convertir el 'milagro de Luján' en historia oficial, vemos un intento de suprimir toda otra posible lectura y todo vestigio de memoria que no garantice su poder y su influencia como fuerza legitimadora de la sociedad ${ }_{.}{ }^{40}$

Estos estudios no siempre diferencian la acción de los distintos sujetos históricos que giran alrededor del culto lujanense. Por eso les cuesta considerar al pueblo creyente como un protagonista y contemplar la posibilidad de que éste acuda a Luján movido por una relación personal con la Virgen más allá de las consignas con las que sea convocado. ${ }^{41}$

A esta dificultad de reconocer la diversidad de actores se suma la tendencia a leer la vida institucional de la Iglesia desde la motivación política, entendida ésta coyunturalmente. Este es un tema complejo. En primer lugar debemos considerar que el Evangelio, con su llamado a construir una fraternidad como hijos de Dios, tiene una evidente dimensión política. Toda la historia del cristianismo está atravesada por su compleja relación con las instancias

40 Eloísa Martín, "La Virgen de Luján: el milagro de una identidad nacional católica», VII Jornadas sobre Alternativas Religiosas en Latinoamérica 27 (1997). https://equiponaya.com.ar/ congresos/contenido/religion/24.htm

41 Una feliz excepción encontramos en el trabajo de M. Barral sobre la recolección de limosnas para la Virgen de Luján en el siglo XVIII. Alli puede verse el despliegue verdaderamente popular que significó en las zonas rurales estas campañas, siempre presididas por una imagen de la Virgen (cf. María Elena Barral, «Limosneros de la Virgen, cuestores y cuestaciones: la recolección de la limosna en la campaña rioplatense, siglo XVIII y principios del XIX», Boletín del Instituto de Historia Argentina y Americana Dr. Emilio Ravignani 18 (1998): 7-33). 
políticas de los pueblos en los que ha sido anunciado. El límite de esta perspectiva es que analiza en un horizonte Iglesia/política temas que merecen mirarse desde el horizonte más amplio Evangelio/política. Más se complejiza la interpretación si a esta polémica relación entre cristianismo y política le sumamos los defectos de los dirigentes cristianos que no siempre hacen política desde el Evangelio. Pero esta deficiencia -que es muchas veces una dolorosa realidad- no puede cegarnos a la posibilidad de que en la Iglesia haya acciones que -dentro de su complejidad- tengan como fin principal el anuncio del Evangelio y que el efecto político inmediato que producen no sea lo que se busca en primer término.

Quienes se aproximen desde esta perspectiva política a los estudios lujanenses fácilmente pueden encontrar -por ejemplo- en el libro de Salvaire primeramente un relato de legitimación institucional antes que una investigación histórica. Como es lógico, Salvaire no era indiferente a su tiempo y su libro está en el marco de una literatura eclesial signada por el enfrentamiento con la modernidad. Sin embargo, el hecho de que el vicentino haya escrito sin abstraerse de los problemas de su tiempo no significa que la principal motivación de su trabajo sea refutar las ideas liberales. Más allá de sus arrestos de polemista, su libro ofrece una historia profusamente documentada según los métodos historiográficos que se aplicaban entonces para redactar la historia eclesiástica. ${ }^{42}$ Por supuesto que a la hora de juzgar el trabajo de Salvaire no podemos olvidar que no estamos frente a un historiador profesional. Sin embargo, a pesar de ser un entusiasta aficionado logró dar a luz una obra que tuvo una muy buena recepción entre los intelectuales de la época. ${ }^{43}$

En caso de que no nos equivoquemos al describir los límites de la perspectiva que estamos bosquejando esto nos ayuda a entender mejor la actitud de investigadores que realizan trabajos va-

42 Todo lo relativo al método historiográfico de Salvaire está detalladamente explicado en: Durán, De la frontera a la villa de Luján: el gran Capellán de la Virgen Jorge Maria Salvaire, CM (1876-1889), 274-294.

43 Cf. Ibid., 300 s. 
liosísimos y -si bien reconocen que el libro de Salvaire «supera con creces a muchos estudios salidos de las academias de la época»-44 reproducen ligeramente críticas hechas en 1916 en las que lo descalificaban como «una obra de estricta propaganda». ${ }^{45} \mathrm{O}$ que arrojen sombras sobre los estudios de Presas sin mayor análisis documental porque -en cosas absolutamente secundarias- el sacerdote plantea conjeturas distintas a las que estos estudiosos eligen. ${ }^{46}$

Otra particularidad que notamos en esta corriente historiográfica tiene que ver con la noción moderna de ciencia y el lugar que le asigna a la teología. Se trasunta la convicción de que un acceso a la historia verdaderamente científico debe ser desde una perspectiva agnóstica. Al respecto puede establecer un puente para el diálogo el pedido que F. Mallimaci le hace a los cientistas sociales de que abandonen un modelo positivista que reproduce -a su manera- «el viejo paradigma de Augusto Comte que diferencia la ciencia de las creencias -teológicas- a las cuales envía a la metafísica ${ }^{47}$

Si comparamos con lo que afirmamos en el punto anterior sobre el estudio de la historia desde una cosmovisión cristiana vemos que la raíz de la diferencia de horizontes está en la noción de providencia. La creencia de que Dios actúa en la historia parece ser la principal piedra de escándalo en este punto. Intentar explicar esto nos llevaría a complejidades que exceden las posibilidades de este artículo. Sin embargo, para entender mejor esta postura debemos reconocer que no siempre la teología supo presentar adecuadamente la acción de Dios en la historia. El abuso al recurso de lo sobrena-

44 Binetti, El augusto recinto. Conflictos y debates tras la construcción de la Basilica de Luján, 84.

45 Binetti y Suárez, Una virgen para el pago: historia y patrimonio del Luján, 1580-1740, 33.

46 Suarez-Binetti en un capítulo titulado La devoción apresada se preguntan por qué Santa María en su crónica no menciona a Juan Oramas como el que vendió la Imagen a Ana de Matos siendo que tendría que haberlo conocido. Conjeturan que era para no hacerlo quedar mal parado porque -si bien había muerto treinta años antes- se trataba de un personaje importante en la Iglesia porteña. Lo llamativo es que señalan la ausencia de esa conjetura en Presas y deducen que a faltas como esa se debe «la escasa prédica de sus investigaciones entre muchos de sus colegas» (ibid., 46).

47 Fortunato Mallimaci, «Ciencias sociales y teología. Los pobres y el pueblo en las teologías de la liberación en Argentina», en La religión ante los problemas sociales, ed. por Verónica Giménez Béliveau (Buenos Aires: CLACSO, 2020), 283-315, 285. 
tural y la confusión de la fe con la vana credulidad ha alimentado en la modernidad la idea de que la fe no soportaría una mirada crítica y compleja de la realidad histórica. Además, no faltaron ocasiones en que se han defendido anacrónicamente esquemas teológicos que respondían a otro contexto y esta lucha ideológica muchas veces llevó a una instrumentalización de la teología para sostener una estructura institucional en decadencia. En esos casos es entendible que el investigador que tiene una cosmovisión agnóstica y escasa o nula formación teológica llegue a pensar que todo ejercicio teológico sobre la historia es un lastre del que hay que desembarazarse. Esto se verifica por ejemplo en la confusión que parecen tener quienes creen que cuando se hace una lectura teológica de la historia se le está asignando intencionalidad religiosa explícita a los protagonistas. Pero eso es materia del primero de los conflictos que queremos abordar en este artículo.

\section{Dos conflictos de interpretación}

\subsection{El origen religioso de Luján}

Desde la perspectiva eclesial el tema es casi una obviedad: Luján nació alrededor de la Virgen. Para ello se considera que la imagen de la Virgen estaba en el pago desde mediados del siglo XVII y fue trasladada al preciso lugar donde se encuentra actualmente cuando la compró Ana de Matos hace ya 350 años. En esos momentos las llanuras bonaerenses estaban casi despobladas. Al poco tiempo se le edifica una capilla que fue bendecida en 1685. Lentamente se fue formando alrededor de la capilla de Luján un pueblo que en 1755 recibió el título de Villa con un documento que decía: «La Villa se llama de Nuestra Señora de Luján, por ser esta milagrosa Sra. su primera fundadora». ${ }^{48}$ En su estandarte real se destacaba bordada la

48 Juan A. Presas, Anales de Nuestra Señora de Luján: trabajo histórico-documental, 1630 2002 (Dunken, 2002), 119. El título de Villa lo concedió el gobernador de Buenos aires José de Andonaegui, el 17 de octubre de 1755. Su valor fue provisorio hasta que Fernando VI -el 30 de 
Imagen de la Inmaculada. Una mirada de fe de ese proceso histórico es lo que llevó a Salvaire a estampar en la rayera que le agregó a la Virgen en 1887 una frase que condensa el sentido común católico: «Es la Virgen de Luján la primera fundadora de esta Villa». ${ }^{49}$

En contraste con esta lectura, varios historiadores del ámbito no confesional sostienen que esta es solo la versión salveriana de la historia y que está más inspirada en los intereses institucionales de la Iglesia que en los hechos históricos. Según esto, la historiografía sobre Luján desarrollada en el ámbito eclesial parte de esta premisa: la "capital de la fe" necesita un origen religioso.

De las investigaciones que hemos podido reseñar, donde hemos visto más extrema esta lectura es en la obra de Didier Marquiegui. ${ }^{50}$ Este historiador lujanense parte de una categoría de análisis de la historia -que no fundamenta- que se basa en la distinción entre la "ciudad mítica" de la "ciudad real". La primera sería la ciudad "ideológica", irreal, idealizada. En cambio la otra sería la ciudad que efectivamente existió. Desde allí sostiene que la historiografía eclesial -marcada por la interpretación de Salvaire- elabora un relato religioso sobre los orígenes de la Villa de Luján que está más acorde a sus intereses confesionales que a la realidad. La Iglesia propone "creer sin ver", por tanto pinta el paisaje de Luján como ciudad mítica y al creyente eso le basta. En cambio, él propone "ver para creer" y para ello intenta describir el origen de la "ciudad real" desde las fuentes documentales.

Partiendo de esas premisas realiza una detallada presentación de la aparición del primer núcleo poblacional considerable hacia

mayo de 1759- lo confirmó mediante una cédula real. Cf. Binetti y Suárez, Una virgen para el pago: historia y patrimonio del Luján, 1580-1740, 126.

49 Lema que al parecer toma de una lámina de la Virgen que circulaba en esos tiempos en la que se la representaba rodeada de un óvalo con una frase textual del auto de erección de la villa de 1775: «La Villa se llama de Nuestra Señora de Luján, por ser esta milagrosa Sra. su primera fundadora». La estampa puede verse en las primeras páginas de: Jorge María Salvaire, Historia de Nuestra Señora de Luján. Su origen, su santuario, su villa, sus milagros y su culto. Torno I (Buenos Aires: Pablo E. Coni, 1885).

$50 \mathrm{Cf}$. Marquiegui, «Para que lo pueble la gente que se conoce derrotada (por los indios). Precisiones documentales sobre los orígenes del Luján urbano». 
1740 en el marco de la problemática de los pueblos de frontera en esos años. No podemos extendernos ahora en reseñarla a pesar de lo valiosa que resulta para entender esas décadas iniciales. Si bien no desconoce el proceso anterior a 1740 alrededor de la Imagen y su capilla, insiste apasionadamente que considerar eso como el origen de Luján es parte de un relato signado por intereses ideológicos. Incluso lamenta que haya historiadores "laicos" -como Binetti- que adhieren a "la teoría del pueblo capilla" y asigna esta postura a actitudes poco académicas como la "obstinación" y a la intención de acomodarse al clima de época que establece la presencia de un papa argentino y los pedidos de canonización del Negro Manuel y de Salvaire. ${ }^{51}$

En una postura no tan extrema están las investigaciones de Suárez y Binetti. Si bien buscan distanciarse de la posición eclesial aceptan que no pudo ser indiferente al movimiento demográfico la existencia de la capilla con su Imagen. Explican el surgimiento de Luján a partir de la confluencia de dos procesos poblacionales:

«En función de la evaluación realizada, podría reconocerse la existencia de dos procesos formativos en Luján Arriba. El primero, iniciado hacia 1620 o 1630, habría sido posible tras la ocupación de las primeras estancias. Dentro de ese periodo, la asignación de un capellán para la zona, en 1685, y la creación del curato, en 1730, habrían consolidado un orden institucional entre residentes que, evidentemente, siguieron ocupando un espacio rural. Finalmente, a partir de 1736, la militarización del lugar -y la deliberada política de Salcedo- señalaría el arranque del segundo proceso, signado por la formación de la localidad y, 15 años después, la creación de la Villa». ${ }^{52}$

A la hora de intentar un diálogo entre las posturas de estos historiadores y la interpretación eclesial creemos que puede ser útil aclarar que ejercer una lectura teológica de la historia no significa asignarle a sus protagonistas una intencionalidad explícitamente religiosa. Esta parece ser la principal confusión de los investigadores sin formación teológica. Interpretan que cuando se dice “origen religioso" se está entendiendo que la gente se establecía en Luján

51 lbid., 31.

52 Binetti y Suárez, Una virgen para el pago: historia y patrimonio del Luján, 1580-1740, 120. 
motivada principalmente por la devoción. Por ejemplo Marquiegui -según un ejemplo que él mismo ofrece- parecería entender que la afirmación de que la Virgen atrajo a sus hijos alrededor suyo debería verificarse con un cuadro similar al de los «indiecitos de ' $\mathrm{La}$ Misión' que en las escenas finales de la película se encolumnan para morir detrás de su sacerdote que lleva en sus manos su custodia». ${ }^{53}$

Como ya hemos explicado en el punto anterior una interpretación teológica no puede desconocer la complejidad de las acciones humanas y el entrecruzamiento de los procesos históricos. Esto vale también para el desarrollo demográfico del Luján temprano y en ese sentido son muy valiosas las precisiones que aportan Marquiegui, Suárez y Binetti. ${ }^{54}$ A partir de todo el material histórico que da cuenta de un proceso de casi cuatro siglos, la teología busca auscultar la acción de Dios a través de la Virgen de Luján. Desde esta perspectiva no hay contradicción entre afirmar que el pueblo se formó alrededor de la Virgen y constatar que el primer núcleo poblacional considerable se estableció algunas décadas después de la llegada de la Imagen. La insignificancia de los orígenes y la lenta germinalidad del proceso poblacional son datos históricos. Desde ellos la teología intenta leer lo que Dios va haciendo en la historia. Esa pobreza inicial, más que de ausencia de acción de Dios remite al teólogo a la lógica evangélica que comienza su acción salvífica desde lo que no cuenta para el mundo.

Por otra parte el hecho de que la motivación de los colonos de la década de 1740 sea protegerse de los indios y no explícitamente devocional no invalida que una interpretación de fe vea el cobijo que les ha significado la Virgen a estos hijos suyos en los sufrimientos de la vida de la campaña. Agreguemos -solo como indicio para reforzar esta interpretación- que la política del gobierno en esa década fue intentar la creación de pueblos en la frontera y solo lo logró en Luján, donde la Virgen ya estaba desde hacía más de medio siglo. ${ }^{55}$

53 Marquiegui, «Para que lo pueble la gente que se conoce derrotada (por los indios). Precisiones documentales sobre los orígenes del Luján urbano», 27.

54 Sólo para no excedernos nos referimos a estos tres investigadores.

55 Binetti y Suárez, Una virgen para el pago: historia y patrimonio del Luján, 1580-1740, 119. 


\subsection{Las motivaciones en la construcción de la Basílica de Luján}

Dejemos ahora las controversias sobre las interpretaciones del primer siglo de Luján y vayamos a las décadas previas a su tercer centenario. La historia de la construcción de la Basílica -que se desarrolló entre 1890 y 1930- es otro tópico de la historia lujanense donde son llamativas las diferencias entre las diversas lecturas. La historiografía eclesial ve en esa obra la visión de Salvaire -apoyado por el arzobispo Aneiros y por los devotos- de hacerle a la Virgen un templo más digno de su grandeza y que exprese la gratitud del pueblo argentino por tantos beneficios recibidos por su intermedio. Durán trae a colación un testimonio de Scarella en el que cuenta que siendo Salvaire un joven misionero francés recién llegado a la Argentina conoce Luján en la peregrinación de 1871 y al volver dice: "una perla tan valiosa merece un estuche de más valor que el que tiene en la actualidad», ${ }^{56}$ refiriéndose al templo colonial que para esa fecha estaba bastante descuidado. A esto se suma la tradición que habla de una promesa que le habría hecho Salvaire a la Virgen en una ocasión que -siendo misionero entre los indios- estuvo a punto de ser lanceado. ${ }^{57}$ Pero lo más concreto representan las exhortaciones que hizo el vicentino exaltando todas las gracias que la Virgen le ha dado al pueblo argentino a lo largo de la historia y cómo éste está llamado a responderle construyéndole un magnífico templo. El Epílogo de su voluminosa Historia de Nuestra Señora de Luján está dedicado a eso.

Es cierto que en la literatura eclesial sobre el tema no suele enmarcarse semejante gesta en el contexto de la historia de la época, muy marcada por el enfrentamiento entre la Iglesia y el Estado moderno. En la década de 1880 en Argentina -como en otros países-

56 Juan Guillermo Durán, «La Basílica Nacional de Luján: el proyecto de su construcción (1887-1890)», Teología 109 (2012): 65-96, 75.

57 Es lo que se conoce como el voto de Salvaire que según algunos tendría tres partes: escribir la historia de la Virgen, gestionar la Coronación Pontificia y hacerle un templo más digno. El mismo Salvaire menciona en dos oportunidades su promesa pero se duda seriamente de que haya ido más allá de la decisión de escribir el libro. Cf. Juan Guillermo Durán, «La historia de la Virgen de Luján (1885): un libro prometido en "apremiante lance"», Teología 87 (2005): 281-330. 
se debatieron algunas leyes que tendían a independizar algunas funciones de la tutela de la Iglesia. Pasaron a la historia como las "leyes laicas". ${ }^{58}$ El Estado en construcción se afirmaba extendiendo su dominio a diversos ámbitos de la vida pública, muchos de los cuales tenían a la Iglesia como principal actor. Además, ésta era cada vez más dependiente de Roma y a nivel mundial se enfrentaba con el desafío de la modernidad que buscaba relegar la religión al ámbito de lo privado. Se encendió una controversia que agitó la opinión pública dividiéndola en "católicos" y "liberales". Las comillas corresponden porque se trató de una polarización tal que "católico" no hacía tanto referencia a las creencias personales sino a la adhesión a las políticas romanas. De hecho, muchos políticos "liberales" comenzaban sus discursos a favor de las leyes laicas haciendo confesión de su fe católica y no faltaban los "católicos" que se consideraban liberales en cuanto a las ideas políticas. ${ }^{59}$ Luego de encendidos debates en 1884 se sanciona la ley 1.420 de "Educación común". La tensión llegó a tal punto que hacia fines de ese año el presidente Julio Roca expulsó al delegado apostólico y rompió relaciones con la Santa Sede. ${ }^{60}$ Ese mismo año se aprobó la ley de Registro civil y en 1888 la de Matrimonio civil relegando aún más la influencia de la Iglesia en la vida pública. Luego de sancionadas estas tres leyes las controversias se fueron apagando y en la década de 1890 las relaciones Iglesia-Estado se desarrollaron con mayor

58 Para profundizar en el desafío que significó para la Iglesia el laicismo del siglo XIX puede verse. A nivel mundial: Giacomo Martina, La Iglesia, de Lutero a nuestros días: época del liberalismo. Vol. 3 (Cristiandad, 1974). A nivel local: Néstor Auza, Catolicos y liberales en la generacion del ochenta (Ed. culturales argentinas, 1992); . Desde una perspectiva no confesional: Fortunato Mallimaci, «Catolicismo y liberalismo: las etapas del enfrentamiento por la definición de la modernidad religiosa en América Latina», en La modernidad religiosa: Europa latina y América Latina en perspectiva comparada, ed. por J. Bastian (México: Fondo de Cultura Económica, 2004), 19-44.

59 Cf. Roberto Di Stefano, «La excepción argentina. Construcción del Estado y de la Iglesia en el siglo XIX», Procesos: revista ecuatoriana de historia 40 (2014): 91-113, 100. 107.

60 Salvaire en su Historia de Nuestra Señora de Luján se refiere al delegado apostólico Matera como «noble e inocente víctima de los enconos liberales de gobernantes descreídos» $y$ como alguien que «alentara y estimulara al autor de esta obra a proseguir sin desmayar la larga empresa acometido para glorificación de Nuestra Madre y Señora de Lujan» (Jorge María Salvaire, Historia de Nuestra Señora de Luján. Su origen, su santuario, su villa, sus milagros y su culto. Tomo /l (Buenos Aires: Pablo E. Coni, 1885), 194). 
armonía. ${ }^{61}$ "Fuego de paja" según la expresión de un historiador especializado en estos temas. ${ }^{62}$

En contraste con la historiografía eclesial, que no suele presentar la construcción de la Basílica en el marco de las disputas políticas de la época, la perspectiva no confesional parece entenderla exclusivamente desde ahí. Fogelman, por ejemplo, considera tanto al libro de Salvaire como la Basílica como "dos exvotos contra el Estado liberal". ${ }^{63}$ En la misma línea va la obra de Binetti El augusto recinto, fruto de su tesis de licenciatura dirigida por Norberto Marquiegui. ${ }^{64}$ Este libro tiene la riqueza de asomarnos a las discusiones que se dieron en Luján alrededor del proyecto de construcción del nuevo templo. En su enfoque da prácticamente por supuesto que la única motivación de la obra tiene que ver con la política coyuntural.

En ese sentido presenta un testimonio contundente. Afirma que el día que se bendijo la piedra fundamental -15 de mayo de 1887${ }^{65}$ se colocó en ella un pergamino sellado que decía que la construcción obedecía a un voto «concebido por el Clero y el Pueblo para purgar y expiar los crímenes cometidos por nuestra Nación». ${ }^{66}$ La cita remite al libro de Scarella en su edición de $1925{ }^{67}$ Sin embargo, hemos ido a verificarla y no encontramos en la crónica de ese día ninguna alusión al contenido del pergamino. Quien sí transcribe traducido del latín el contenido del pergamino es Durán y allí no figura la frase aludida por Binetti. ${ }^{68}$ Fuimos a los primeros ejemplares de La Perla del Plata

61 De hecho en 1896 Salvaire abocado a la construcción del Colegio-Seminario elige como padrino de la iniciativa al expresidente Julio Roca, el gran enemigo de la Iglesia en la década anterior. Cf. Durán, De la frontera a la villa de Luján: los comienzos de la gran basilica: Jorge Maria Salvaire, CM, 1890-1899, 426.

62 Di Stefano, «La excepción argentina. Construcción del Estado y de la lglesia en el siglo $X \mid X \gg, 101$.

63 Fogelman, «Dos exvotos contra el Estado liberal: la Basílica y el libro de Salvaire sobre la historia del culto de Luján», 25-49.

64 Binetti, El augusto recinto. Conflictos y debates tras la construcción de la Basilica de Luján.

65 La bendición de la piedra fundamental se realizó como cierre de la octava de la fiesta de la Coronación Pontificia.

66 Binetti, El augusto recinto. Conflictos y debates tras la construcción de la Basilica de Luján, 97.

67 Scarella, Pequeña historia de Nuestra Señora de Luján. Su culto, su santuario y su pueblo, 257.

68 Durán, De la frontera a la villa de Luján : el gran Capellan de la Virgen Jorge María Salvaire, $C M(1876-1889), 463$. 
(LPP) a verificar la cita de Durán y es correcta. ${ }^{69}$ Pero también encontramos en esos años iniciales de la revista, además de la crónica de la bendición de la piedra fundamental fechada en 1891 referida por Durán, un artículo sobre el simbolismo de la Basílica en 1893 donde vuelve a transcribirse el texto del pergamino y esta vez sí incluye la frase que alude a la función expiatoria del nuevo templo. ${ }^{70}$

Más allá de esta curiosidad heurística que queda por dilucidar, la frase en cuestión era común en la retórica eclesial de la época. Para interpretarla mejor podemos leerla en su contexto:

«Hallándose el Templo dedicado a la Bienaventurada Virgen de Luján, enriquecido por la devoción de nuestros mayores por tantos monumentos de la piedad; y siendo sensible que hubiese caído en la más lamentable condición por la injuria de los tiempos; siendo además evidente a los ojos de todos su estrechez para congregar a todos los que aquí acudían a orar; para que el culto hacia la misma Madre de Dios resplandeciese más y más; y con el objeto de dar satisfacción a los repetidos clamores así del Clero como de todo el Pueblo argentino, León Federico Aneiros... cumpliendo un voto concebido por el Clero y el Pueblo para purgar y expiar los crímenes cometidos por nuestra Nación, bendijo esta piedra de feliz auspicio... ${ }^{71}$

Como podemos apreciar, el documento expresa múltiples motivaciones entre las que se destaca la necesidad de un nuevo templo debido al mal estado del actual y a lo reducido que resultaba para la afluencia de peregrinos de estos tiempos. Para ser fieles al primero de los preceptos de Lonergan, sé atento, debemos evitar la tendencia a una lectura que tienda a homogeneizar la multiplicidad de causas.

Otro documento de primera mano que puede ayudarnos a comprender las motivaciones de Salvaire para impulsar semejante empresa lo encontramos en el Epílogo de su Historia de Nuestra Señora de Luján dedicado por entero a exhortar a los devotos a poner manos a la obra en la construcción de un nuevo templo. Un Santuario

69 LPP 69, 26 de abril de 1891, 276-277.

70 LPP 196, 15 de octubre de 1893, 682-683. Este artículo está firmado por las siglas J.M.S. lo que nos hacer pensar que está mejor informado del contenido del pergamino que el cronista de 1891 que no firma su nota.

71 lbid. 
Nacional. ${ }^{72}$ En esas dieciséis páginas abunda en la necesidad de una obra que exprese la gratitud que el pueblo argentino le tiene a la Virgen por la innumerable cantidad de portentos con que ella lo favoreció. Un monumento espléndido, según los más perfectos modelos de la arquitectura religiosa. Digno de algo tan valioso como la Santa Imagen que acompañó dos siglos y medio el peregrinar del pueblo argentino. Para ello propone -y fundamenta largamente- el estilo gótico. La única referencia al contexto político se encuentra en la transcripción que hace de una carta de apoyo del arzobispo Aneiros en la que le dice que «en días luctuosos como los que atravesamos» la construcción de un hermoso Santuario Nacional «sería para todos los patriotas cristianos, como el faro radiante que a todos indicara el puerto de la salvación social». ${ }^{73}$ Por supuesto que Salvaire no era ingenuo y podía calibrar el significado social de la iniciativa que proponía, pero -según se desprende de este Epílogopara él la construcción era primeramente una gesta de amor a la Virgen llevada adelante por el pueblo creyente. El libro concluye exhortando a una obra en que las piedras hablen del amor entre la Virgen y su pueblo:

«O Argentinos, tiernos devotos de la Virgen de Luján! levantad pues un Santuario digno de vuestra excelsa Patrona; y que sus muros majestuosos narren a las generaciones venideras, las misericordias de María y vuestro tradicional amor hacia Ella. Lapides clamabunt $\gg .{ }^{74}$

Digamos también que Salvaire no fue el único actor en la construcción de la Basílica y unas pudieron ser sus intenciones,

72 Esta era una tendencia en otros países de mayoría católica con un estado nacional en formación.

73 Salvaire, Historia de Nuestra Señora de Luján. Su origen, su santuario, su villa, sus milagros y su culto. Tomo II, 495.

$74 \mathrm{lbid}$., 496. Para este fin -que las piedras hablen del amor del pueblo argentino a MaríaSalvaire habia tomado una idea de los franceses que recientemente habían edificado la Basílica del Sagrado Corazón de Jesús en Montmartre. Lanzó una suscripción para colaborar con $\$ 10 \mathrm{~m} / \mathrm{n}$ por piedra. A cada una se le practicó una incisión en la cara superior de modo tal que se pueda. colocar en su interior un pequeño frasco de vidrio. Allí se depositaba el nombre del bienhechory de su familia con alguna petición y luego se lo lacraba. Al mismo tiempo se grababa en la parte exterior de cada sillar nombres o inscripciones a voluntad del donante como puede verse hasta el día de hoy (cf. Durán, De la frontera a la villa de Luján: los comienzos de la gran basílica: Jorge María Salvaire, CM, 1890-1899, 118). 
otras las del arzobispo Aneiros, otras las de los católicos "notables" que los rodeaban y otras las del pueblo que respondió a la iniciativa. A este respecto hay que señalar que la edificación de un monumental templo neogótico requería un enorme esfuerzo económico y fue convocada en tiempos en que el país atravesaba una profunda crisis económica que algunos hoy llaman el pánico de 1890. A pesar de todas las contrariedades, la Basílica se construyó costeada enteramente por la limosna de los devotos. Si bien Salvaire en 1896 solicitó un subsidio al gobierno con el fin de adelantar las obras y poder inaugurar el Santuario Nacional en las fiestas del Centenario, el capellán murió en 1899 sin obtener respuesta. ${ }^{75}$ En los poco más de cuarenta años que duraron las obras nunca faltaron los recursos. ${ }^{76}$ La experiencia demostró que la confianza ilimitada de Salvaire -y Aneiros- en la generosidad del pueblo argentino tuvo un firme asidero en la realidad.

Queda pendiente una investigación más profunda en los documentos de la época para interpretar más cabalmente lo que pudo haber significado la obra para sus contemporáneos. Pero, con lo presentado hasta el momento, creemos que es una interpretación desbalanceada entender que haya sido un ejercicio de militancia católica contra el liberalismo la construcción de una obra monumental, que llevó más de cuarenta años y que contó con el aporte de miles de devotos.

\section{Conclusión}

Lonergan explica que el ejercicio de la dialéctica en la teología está orientado a producir una conversión en clave de ampliación de horizontes. ${ }^{77}$ En ese sentido nos hemos visto muy beneficiados en este

$75 \mathrm{El}$ hecho de que alguna vez se haya dicho que se quería terminar en veinte años y haya llevado cuarenta repite un patrón común en la mayoría de este tipo de obras realizadas al ritmo del óbolo de los fieles.

76 Durán, «La Basílica Nacional de Luján: el proyecto de su construcción (1887-1890)», 92.

77 Lonergan, Método en teología, 229s. 
acercamiento a estudios históricos ajenos hasta hace poco a nuestros ámbitos de interés. Confiamos en que esta nueva perspectiva nos ayudará a enriquecer la reflexión teológica sobre el misterio de Luján.

Nos queda la convicción de que es mucho lo que pueden fecundarse ambas corrientes con el diálogo y la interacción. Una mirada indiferente al significado teológico de lo que sucede en Luján podrá describir hechos pero siempre tendrá sabor a incompleta ante tanta exuberancia vital. Por otra parte un discurso eclesial que ignore los trabajos históricos de investigadores serios y responsables correrá el riesgo de quedar atrapado en una retórica de corralito (en tiempos en que la mayoría de las ovejas prefieren el campo abierto).

Nuestra fe nos lleva a pensar que es tan potente la presencia de la Virgen de Luján en el corazón del pueblo argentino que allí se cifra un misterio de la acción salvífica de Dios. Misterio que tiene que ver con la función que Jesús le encomendó a María al pie de la cruz: ser Madre. Y una madre lo primero que hace es unir, reunir a sus hijos alrededor de ella para llevarlos a Cristo. Este encargo es el que estuvo cumpliendo durante estos casi cuatro siglos en Luján. Tal vez no todos podamos reconocernos en el lema estampado en la rayera que la entiende como la primera fundadora de este pueblo. Pero hay otra frase que creemos que en el fondo significa lo mismo. Fue aquella que hace mucho tiempo un padre argentino le dijo a sus hijos y que hasta el día de hoy resuena especialmente en nuestros corazones: «los hermanos sean unidos porque esa es la ley primera».

\section{Bibliografía}

Binetti, Jesús, El augusto recinto. Conflictos y debates tras la construcción de la Basílica de Luján. Luján: Librería de Mayo, 2007.

Binetti, Jesús - Suárez, Federico, Una virgen para el pago: historia y patrimonio del Luján, 1580-1740. Ituzaingó: Cienflores, 2016.

Di Stefano, Roberto - Zanca, José, «Iglesia y catolicismo en la Argentina: medio siglo de historiografía», Anuario de Historia de la Iglesia (2015): 15-45. 
Durán, Juan Guillermo, De la frontera a la villa de Luján: el gran Capellan de la Virgen Jorge María Salvaire, CM (1876-1889). Buenos Aires: Bouquet Ed., 2008.

Durán, Juan Guillermo, «La Basílica Nacional de Luján: el proyecto de su construcción (1887-1890)», Teología 109 (2012) 65-96.

Durán, Juan Guillermo, Jorge María Salvaire, C. M., Gran apóstol de la Virgen de Luján, "Cual otro Negro Manuel". Buenos Aires: Talita Kum Ediciones, 2016.

Figueroa, Pablo, «Hacia una fundamentación del hacernos a nosotros mismos en la ética existencial metódica de B. Lonergan». En: Teología S. A. D., Dar razón de nuestra esperanza. El anuncio del Evangelio en una sociedad plural. XXX Semana Argentina de Teología. Buenos Aires: Agape libros, 2012, 467-476.

Fogelman, Patricia, «Dos exvotos contra el Estado liberal: la Basílica y el libro de Salvaire sobre la historia del culto de Luján». En Fogelman P.-Ceva M.-Touris C., El culto mariano en Luján y San Nicolás: religiosidad e historia regional. Buenos Aires: Biblos, 2013, 25-49.

Lonergan, Bernard, Método en teología. Salamanca: Sígueme, 20064. Mallimaci, Fortunato, «Ciencias sociales y teología. Los pobres y el pueblo en las teologías de la liberación en Argentina». En Giménez Béliveau V., La religión ante los problemas sociales, Buenos Aires. CLACSO: 2020, 283-315.

Marquiegui, Dedier, «Para que lo pueble la gente que se conoce derrotada (por los indios). Precisiones documentales sobre los orígenes del Luján urbano», Red Sociales. Revista del Departamento de Ciencias Sociales 6 (2019): 13-56.

Martín, Eloísa, «La Virgen de Luján: el milagro de una identidad nacional católica», VII Jornadas sobre Alternativas Religiosas en Latinoamérica 27 (1997) [en línea] https://equiponaya.com.ar/ congresos/contenido/religion/24.htm [consulta: 8/5/2021].

Presas, Juan A., Nuestra Señora de Luján: estudio crítico-histórico: 1630-1730. Buenos Aires, Junta Catequística Diocesana de Morón, 1980.

Presas, Juan A., Anales de Nuestra Señora de Luján: trabajo histórico-documental, 1630-2002. Buenos Aires: Dunken, 2002. 
Salvaire, Jorge María, Historia de Nuestra Señora de Luján. Su origen, su santuario, su villa, sus milagros y su culto. Tomos I y II. Buenos Aires: Pablo E. Coni, 1885. 